International Journal of Engineering \& Technology, $11(1)(2022) 1-9$
International Journal of Engineering \& Technology
SPC
Website: www.sciencepubco.com/index.php/IJET
Research paper

\title{
Thermo mechanical and microstructural constituents of dissimilar S700MC-S960QC high-strength steel welded joints using overmatched filler wire
}

\author{
Francois Njock Bayock ${ }^{1}$ *, Marius Tony Kibong ${ }^{2}$, Sadrack Timba $^{1}$, Nji Nelson Che ${ }^{3}$ \\ ${ }^{1}$ Department of Mechanical Engineering, ENSET Douala, University of Douala, P.O. Box: 1872, Douala, Cameroon \\ ${ }^{2}$ Laboratory of Technologies and Applied Sciences, University Institute of Technology, University of Douala, \\ PO Box 8698 Douala, Cameroon \\ ${ }^{3}$ Laboratory of Energy Materials Modelling and Methods, EDSPD, University of Douala, P.O. Box: 2701 Douala, Cameroon \\ *Corresponding author E-mail: njockfm1@outlook.com
}

\begin{abstract}
In this study, a mechanical and microstructural constituent of welded joints of dissimilar high-strength and ultra-high-strength steels (S700MC/S960QC) using overmatched filler wire was evaluated. Three different heat inputs $(18 \mathrm{~kJ} / \mathrm{cm}, 8 \mathrm{~kJ} / \mathrm{cm}$, and $10 \mathrm{~kJ} / \mathrm{cm})$ and overmatched filler wire were applied using the GMAW process. Micro-hardness measurement was conducted using Vickers hardness test, tensile test, and microstructural constituents by scanning electron microscopy (SEM) and energy-dispersive X-ray spectroscopy (EDS) were performed in this analysis. A dissimilar welded sample with a cooling time of $51 \mathrm{~s}(18 \mathrm{~kJ} / \mathrm{cm})$ showed a substantial hardness reduction in the fine grain heat-affected zone (HAZ) of the S700MC steel side, which was between 220-240 HV5. The cause could be the increase of heat input but also the use of overmatched filler wire, which can be the result of an increase of ferrite to austenite formation in the HAZ. SEM/EDS results confirmed the increase of carbide clusters, and tempered Martensite in the CGHAZ of the S960QC side, and ferrite-bainite on the S700MC side. An increase in the presence of high carbide content and the formation of Ni, Mo, and Mn were observed on the S960QC side. The increase of carbide formation in the CGHAZ of both sides reduced the hardness and strength of the welded joints. The tensile test confirms the softening observed in the FGHAZ of the S700MC side, which caused the joint fracture on this side during the test.
\end{abstract}

Keywords: Dissimilar Welding; GMAW Process; Overmatched Filler Wire; Hardness Test; Microstructural Constituents; SEM Images; EDS Micrographs.

\section{Introduction}

Manufacturing companies nowadays need some materials that are light in weight and strong in their functions. In other to achieve this gold, materials that have different mechanical properties and chemical compositions can be combined [1-3]. It is also necessary to have an idea about the production process meaning that, the material has a different transformation process during its production. The advantage of these new materials is their ability to be applied in cold and hot environments [4], [5]. The issue of welding dissimilar materials is because every material has its base mechanical properties, chemical compositions, production processes, and welding procedure according to ISO 15614-1. 2017 standards [6]. The improvement of the welded joint characteristics is the main problem to solve. By increasing softening the heat-affected zone (HAZ) of dissimilar welded joints of high-strength and ultra-high-strength steel when using overmatched filler wire can lead to the beneficial outcomes of lighter weight and increase of strength in the HAZ [5], [7], [8].

The gas metal arc welding process (GMAW) is an arc welding process that is suitable for welding high and ultra-high-strength steels [913]. Welding of dissimilar high-strength and ultra-high-strength steel is a difficult task that depends mainly on the heat source parameter for it to improve mechanical properties in the HAZ [14-16]. In addition to the heat input, it is also important to take into account the geometric parameters, filler wire properties (whether it is under matched, matched, or overmatched), and the welding process that can be applied. Nowadays some steel manufacturing companies focus their researches on the heat treatment steels process, which impacted the chemical and mechanical properties of metals. It can be seen that the steel manufacturing process is also one of the parameters that can influence the weldability of dissimilar high and ultra-high-strength steels.

Thermomechanically Controlled Processing (TMCP) for S700MC is the process that requires paying attention to the joint geometry, plate thickness, and also chemical composition of the steel being treated [17-19]. The literature shows that higher heat can be the result of grain refinement of the final microstructure at the maximum temperature of Tmax $\geq 1150^{\circ} \mathrm{C}$ [20-22]. It is the temperature range of the suppressed recrystallization. On the 960QC side, this steel has a higher strength of more than $900 \mathrm{MPa}$ and above [4], [11], [23]. The production process is obtained by carefully defined chemical composition and manufacturing methods used [24, 25]. Nevertheless, it is 
very important to define the favorable heat input which would develop good weldability of the welded joints. It is essential to know the correlation between heat input-mechanical properties of the welded joint and microstructural constituents in the HAZ [23], [26], [27]. Overmatched filler wire has a particularity that its mechanical properties are higher than the bases materials properties [28 - 30]. The increase of filler wire properties can be the cause of higher hardness in the weld zone which can develop softening zones notably in the fine grain heat-affected zone (FGHAZ) and coarse-grain heat-affected zone (CGHAZ) of the welded joints [31, 32]. The issues of welding dissimilar high and ultra-high-strength steel with overmatched filler wire will resume defining optimum mechanical properties and microstructural characterization especially in the FGHAZ, which is always the most affected by softening in the HAZ [33]. This research focused on the mechanical properties (Hardness, Tensile) and the microstructural characterization (the spray of carbon, Bainite, ferrite, austenite constituent and the evolution of $\mathrm{Mn}, \mathrm{Cr}$, Ni constituent in the FGHAZ of the welded joints) [34], [35]. An experimental analysis was set up in this research. The welding process using the GMAW process of dissimilar S700MC/S960QC using an overmatched filler wire was applied followed by different mechanical tests such as tensile and hardness tests. The microstructural characterization in the FGHAZ microstructure analysis of both sides of the dissimilar welded joints was applied using SEM/EDS structures formed. The results of this research allowed us to synchronize the effect of heat input and overmatched filler wire on the mechanical properties and microstructural constituents on the HAZ of dissimilar welded joints. The best combination of heat input and overmatched filler wire can be defined in other to obtain optimum mechanical properties and microstructural constituents of these particular dissimilar welded joints.

\section{Experimental setup}

\subsection{Welding procedure}

In this experimental procedure, two types of steels were used, namely S700MC (EN 10149-2) and S960QC (EN10051). Gas metal arc welding using shielding gas of $\mathrm{Ar}+18 \% \mathrm{CO}_{2}$, with a flow rate of $18 \mathrm{~L} / \mathrm{min}$, and an automatic robotic system where a Thermo cycle sensor was installed. The power source was a Fronius Pulls Synergic 5000 connected to a unit wire feeder. The welding process was performed according to the welding procedure specification (WPS) following ISO 15614-1. 2017 standards [6]. The thermocouple sensor readied and analyzed a Thermo cycle during the welding process [19]. Table 1 shows the different parameters of the welding process which were used to weld samples. For all samples, the first pass remained at the heat source value of $8 \mathrm{~kJ} / \mathrm{cm}$. they were some variations when applied to the second pass. Three heat inputs were applied on the second passes which were $8 \mathrm{~kJ} / \mathrm{cm}, 10 \mathrm{~kJ} / \mathrm{cm}$, and $18 \mathrm{~kJ} / \mathrm{cm}$.

Table 1: Welding Conditions Showing Parameters of Three Samples

\begin{tabular}{|c|c|c|c|c|c|c|c|c|c|c|c|}
\hline $\begin{array}{l}\text { Welded } \\
\text { samples }\end{array}$ & Pass 1 & & & & & & Pass 2 & & & & \\
\hline & $\begin{array}{l}\text { Filler wire } \\
\text { designation }\end{array}$ & $\begin{array}{l}\text { Current } \\
{[\mathrm{A}]}\end{array}$ & $\begin{array}{l}\text { Voltage } \\
{[\text { V] }}\end{array}$ & $\begin{array}{l}\text { Welding } \\
\text { speed[cm/min] }\end{array}$ & $\begin{array}{l}\text { Heat } \\
\text { input } \\
{[\mathrm{kJ} / \mathrm{cm}]}\end{array}$ & $\begin{array}{l}\text { Torch } \\
\text { angle } \\
{\left[{ }^{\circ}\right]}\end{array}$ & $\begin{array}{l}\text { Current } \\
{[\mathrm{A}]}\end{array}$ & $\begin{array}{l}\text { Voltage } \\
{[\text { V] }}\end{array}$ & $\begin{array}{l}\text { Weld } \\
\text { speed[cm/min] }\end{array}$ & $\begin{array}{l}\text { Heat } \\
\text { input } \\
{[\mathrm{kJ} / \mathrm{cm}]}\end{array}$ & $\begin{array}{l}\text { Torch } \\
\text { angle }\left[{ }^{\circ}\right]\end{array}$ \\
\hline Sample 1 & EN ISO & 215 & 25.30 & 37.30 & 8 & 7 & 212 & 27.30 & 28 & 8 & 7 \\
\hline Sample 2 & $1683-\mathrm{A}-$ & 215 & 25.30 & 37.30 & 8 & 7 & 203 & 28.00 & 24 & 10 & 7 \\
\hline Sample 3 & G 696 M 21 & 215 & 25.30 & 37.30 & 8 & 7 & 205 & 27.00 & 18 & 18 & 7 \\
\hline
\end{tabular}

Three specimens of dissimilar high strength and ultra-high-strength steels (S700MC/S960QC) having the dimensions of $300 \mathrm{X} 200 \mathrm{X} 8$ $\mathrm{mm}^{3}$, a V groove butt joint with a $2 \mathrm{~mm}$ gap, an angle of $60^{\circ}$ were used in this experiment to weld different samples. Table 2 presents the chemical compositions, mechanical properties of base materials and filler wire. The different parameters such as Yield strength (YS), ultimate tensile strength (UYS), elongation \% (A5), and the base materials hardness (HV5) of both plates of steel and filler wire can be seen in the Table. From those initials' mechanical properties and chemical compositions of base materials, the comparison will be made after applying several tests. It can be noticed from the table that the mechanical properties of the filler wire are a bit higher than both BM. The choice of using overmatched filler wire can affect the welded joints properties depending also on the welding heat input values applied.

Table 2: Chemical Composition and Mechanical Properties of Base Materials (S700MC/S9600C) and Filler Wire

\begin{tabular}{|c|c|c|c|c|c|c|c|c|c|c|c|c|c|c|c|c|}
\hline \multicolumn{17}{|c|}{ Chemical composition, wt \% } \\
\hline Materials & $\mathrm{C}$ & $\mathrm{Si}$ & $\mathrm{Mn}$ & $\mathrm{Al}$ & B & $\mathrm{Nb}$ & $\mathrm{Ti}$ & $\mathrm{V}$ & $\mathrm{Cu}$ & $\mathrm{Cr}$ & $\mathrm{Ni}$ & Mo & $\mathrm{N}$ & $\mathrm{P}$ & $\mathrm{s}$ & $\mathrm{CE}$ \\
\hline $\begin{array}{l}\text { S700MC } \\
\text { (EN10149- } \\
\text { 2) }\end{array}$ & 0.056 & 0.16 & 1.18 & 0.027 & 0.002 & 0.044 & 0.12 & 0.006 & 0.02 & 0.062 & 0.066 & 0.015 & 0.005 & 0.01 & 0.005 & 0.38 \\
\hline $\begin{array}{l}\text { S960QC } \\
\text { (EN10051) }\end{array}$ & 0.09 & 0.21 & 1.05 & 0.03 & 0.002 & 0.003 & 0.032 & 0.008 & 0.025 & 0.82 & 0.04 & 0.158 & 0.175 & 0.01 & 0.004 & 0.49 \\
\hline $\begin{array}{l}\text { (EN ISO } \\
\text { 16834-A-G } \\
895 \text { M21) }\end{array}$ & 0.12 & 0.21 & 1.9 & - & - & - & - & - & 0.30 & 0.45 & 2.35 & 0.55 & - & - & - & 0.34 \\
\hline \multicolumn{17}{|c|}{ Mechanical properties } \\
\hline \multicolumn{2}{|l|}{$\begin{array}{l}\text { S700MC } \\
\text { (EN 10149-2) }\end{array}$} & \multicolumn{3}{|l|}{768} & \multicolumn{4}{|l|}{822} & \multicolumn{4}{|l|}{12} & \multicolumn{4}{|l|}{280} \\
\hline \multirow{2}{*}{\multicolumn{2}{|c|}{$\begin{array}{l}\text { S960QC (EN10051) } \\
\text { (EN ISO 16834-A- }\end{array}$}} & \multicolumn{3}{|l|}{960} & \multicolumn{4}{|l|}{1000} & \multicolumn{4}{|l|}{18} & \multicolumn{4}{|l|}{320} \\
\hline & & 960 & & & \multicolumn{4}{|l|}{1038} & \multicolumn{4}{|l|}{20} & \multicolumn{4}{|l|}{390} \\
\hline
\end{tabular}

\subsection{Test of welded samples}

In this test, Wilson Wolpert 452SVD Vickers hardness tester machine in the Laboratory of Welding Technology of LUT-University, Finland was used to carry out Hardness tests. The hardness measurements were carried out when a load of $5 \mathrm{kgf}$ was applied, dwell time measurements were $20 \mathrm{~s}$ and at least 45 random measurements across the specimen were applied. In the same laboratory, a tensile test was carried out using ZWICK/ROZ Z300 RED equipment. According to EN ISO 6892-1:2016 [36], six specimens were well prepared 
(two per sample). To carry out microstructural constituents in the different HAZ points of specimens, scanning electron microscope (SEM) and energy-dispersive X-ray spectroscopy (EDS) tests were conducted using Hitachi SU3500 equipment. The different specimens were well prepared by polishing and etching at the solution of $4 \%$ of solution of HNO3 in ethanol during 20 s. Figure 1 shows a Macro morphology of dissimilar welded joints (S700MC-S960QC). It can be seen in Figure 1a the HAZ of both materials.

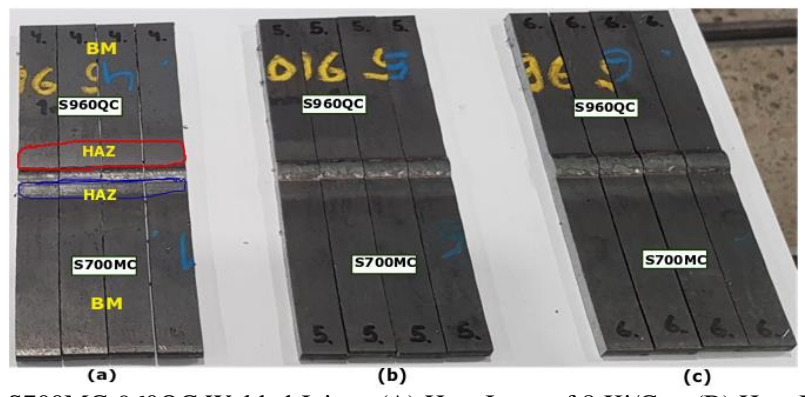

Fig. 1: Macro Morphology of Dissimilar S700MC-960QC Welded Joints. (A) Heat Input of $8 \mathrm{Kj} / \mathrm{Cm}$; (B) Heat Input of $10 \mathrm{Kj} / \mathrm{Cm}$; and (C) Heat Input of $18 \mathrm{Kj} / \mathrm{Cm}$.

\section{Experimental results}

\subsection{Vickers hardness analysis of welded joints}

The main objective when welding dissimilar high and ultra-high-strength is the improvement of mechanical properties of the welded joint. Hardness tests have been carried out in this section 3 specimens which were well prepared according to ISO 6507-1:2018 standard [37]. Figure 2 shows the hardness profile of dissimilar welded samples. The Vickers hardness mapping profile across the welded joints was measured by using one line per sample and point by point over the entire line. To measure the point line, a load of $0.50 \mathrm{kgf}$ was applied and the loading/unloading rate of $0.50 \mathrm{~N} / \mathrm{min}$ was performed in this experiment. The dwell time measurement was fixed at $20 \mathrm{~s}$ and a total of 3 samples were tested in this section. The results presented the hardness profile generated in Figure 2a, which showed a higher hardness occurrence on the weld metal. In the S960QC side, the lowest hardness value was observed in the fine grain heat-affected zone (FGHAZ) of the welded joint and had a value of 290 HV5 thus, a difference of 30 HV5 compared to the BM in the S700MC side, which was the most impacted during the welding process, has the lowest hardness value of 192 HV5 in the FGHAZ. Compared to the base material, the difference was 88 HV5. Figure $2 \mathrm{~b}$ shows the hardness profile when heat input of $10 \mathrm{~kJ} / \mathrm{cm}$ is applied. The result presented a continuous decrease of hardness in the S700MC side of the welded joints. The value was $160 \mathrm{HV} 5$ which compared to the BM, had a difference of $120 \mathrm{HV}$. On the S690QT side, the softening area was also located in the FGHAZ. The lowest hardness value was approximately $290 \mathrm{HV} 5$, which was less than the BM. Figure 2c represents the last test being the result of hardness distribution when heat input of $18 \mathrm{~kJ} / \mathrm{cm}$ is applied during the welding sample. This figure shows the hardness profile, which has developed softening on the FGHAZ due to an increase of heat input and also the use of overmatched filler wire. The results show the lowest hardness value on the S700MC side was approximately $130 \mathrm{HV} 5$ so with a difference of $150 \mathrm{HV} 5$ compared to the BM. On the S960QC side, it was the same observation regarding the softening area of the welded sample. The lowest hardness value was 275 HV5, which was less than the BM. An increase of hardness was observed on the weld metal. From all samples, the average hardness values were 470 HV5, higher than the BM. The reason for this increase was that the filler wire itself was overmatched and also the increase of heat input which was an object of carbide diffusion in the HAZ of the welded joints. 


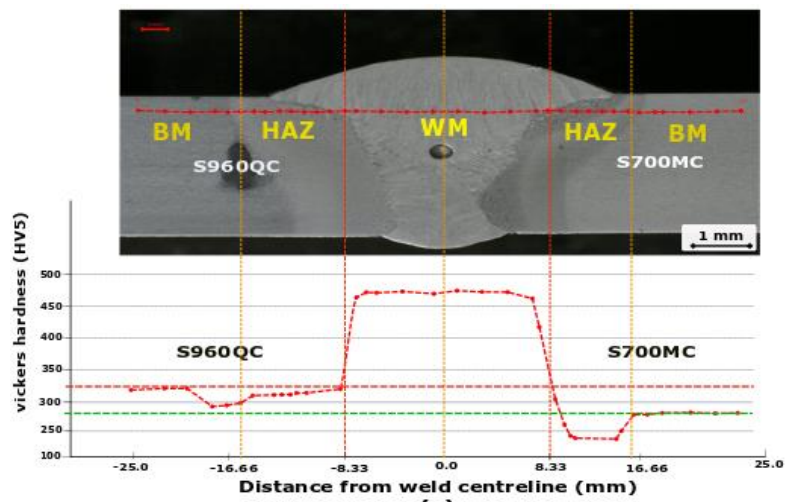

(a)

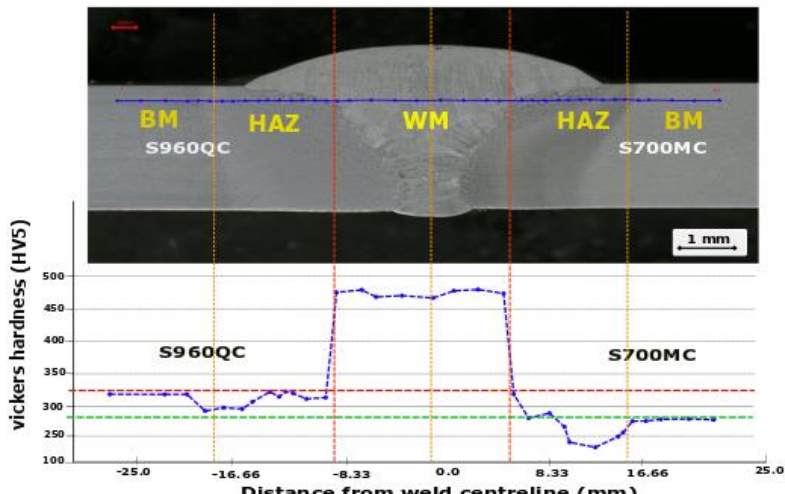

(b)

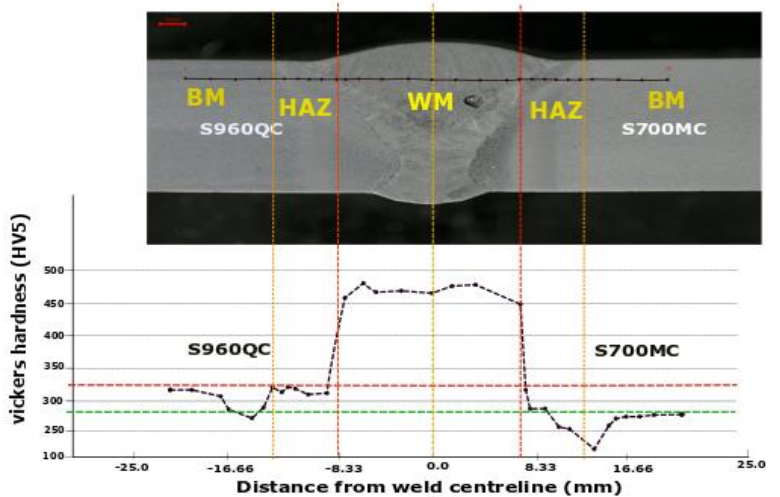

(c)

Fig. 2: Welded Joints Cross-Section Showing Vickers Hardness Profiles of Dissimilar S700MC/S960QC Steels: (A) Vickers Hardness Profile of 7 Kj/Cm, (B) Vickers Hardness Profile of $10 \mathrm{Kj} / \mathrm{Cm}$, and (C) Vickers Hardness Profile of $17 \mathrm{Kj} / \mathrm{Cm}$.

\subsection{Microstructural analysis of welded joints}

Figure 3 presents macro and SEM images on the FGHAZ of dissimilar welded joints of S700MC/S960QC when a heat input of $8 \mathrm{~kJ} / \mathrm{cm}$ is applied. Figure 3a shows the SEM image in the FGHAZ of S700MC HAZ. FGHAZ refers to the HAZ that was subject to the decrease of hardness. Based on the thermo-cycle due to the heat input and overmatched filler wire applied during the welding process, there is a confirmation of more Bainite (B) and ferrite a little amount of ferrite (F) at the hardness value of 192 HV5. They were also a little amount of carbide across the grain boundary. In the S960QC side (Figure 3b), a formation of Bainite + Martensite (B+M) in the microstructure was observed. The weld metal microstructure was mainly formed by an acicular ferrite with some trace of Bainite. 

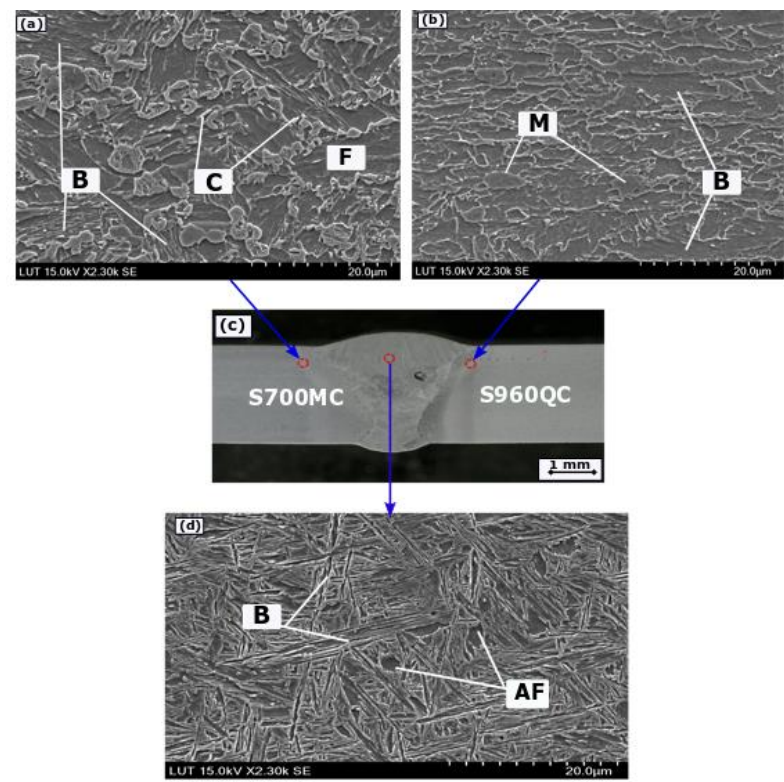

Fig. 3: Macro Images and SEM Images of FGHAZ Showing the Microstructure Phase Transformations when Applied Heat Input of $8 \mathrm{Kj} / \mathrm{Cm}$ : (A) SEM Images of FGHAZ of S700MC, (B) SEM Images of FGHAZ Of S960QC, (C) Macro Images, and (D) SEM Images of WM.

Figure 4 shows macro images, and SEM pictures on the FGHAZ of dissimilar S700MC/S960QC welded sample of heat input of 10 $\mathrm{kJ} / \mathrm{cm}$. SEM micrograph of S700MC (Figure 4a) confirmed an increase of carbide content and Ferrite (F) due to the increase of heat input value. In the same micrograph, they was also an appearance of Bainite (B) on the microstructure. SEM micrograph of S960QC (Figure 4b) revealed the transformation of Martensite (M), B, Tempered Martensite (TM), and some trace of Retained of Austenite (RA). SEM analysis shown in Figure 4d revealed mainly the formation of acicular ferrite (AF) and a little amount of pro-eutectoid ferrite (PF) in the microstructure.
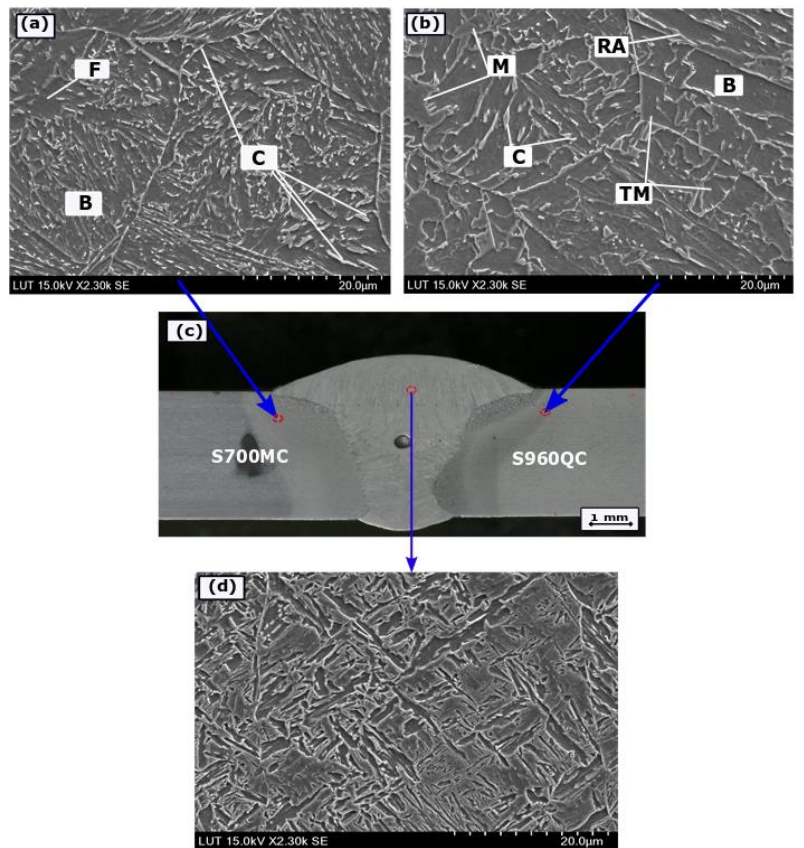

Fig. 4: Macro Images and SEM Images of FGHAZ Showing the Microstructure Phase Transformations when A Heat Input of $10 \mathrm{Kj} / \mathrm{Cm}$ Is Applied: (A) SEM Images of FGHAZ of S700MC, (B) SEM Images of FGHAZ Of S960QC, (C) Macro Images, and (D) SEM Images of WM.

Micro images and SEM micrographs on the FGHAZ of dissimilar welded samples of S700MC/S960QC using heat input of $18 \mathrm{~kJ} / \mathrm{cm}$ are shown in Figure 5. The SEM micrograph of Figure 5a mainly consisted of F with a consistent amount of carbide diffusion, and some amount of $\mathrm{B}$ in the microstructure. The consequence of the increase of the amount of carbide is related to the higher heat input value, and also the use of overmatched filler wire. It can be seen in the same micrograph some dark points which can be defended as some RA. In the S960QC side (Figure 5b), the mixture of B-M as shown in the microstructure followed by tempered Martensite (TM) due to a higher heat input when welding sample. They were an appearance of some carbide diffusion on the microstructure. The microstructure of WM was essentially the formation of acicular ferrite (AF) and Widmanstätten ferrite (WF). 


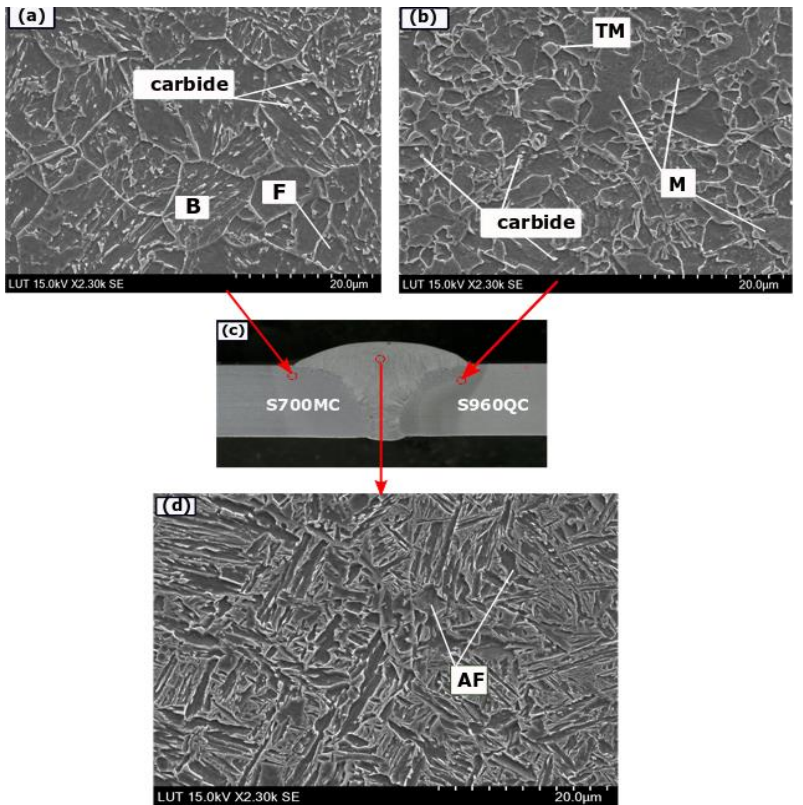

Fig. 5: Macro Images and SEM Images of FGHAZ Showing the Microstructure Phase Transformations when Applied Heat Input of 18 Kj/Cm: (A) SEM Images of FGHAZ of S700MC, (B) SEM Images of FGHAZ of S960QC, (C) Macro Images, and (D) SEM Images of WM.

Figure 6 gives the results of EDS point analysis across the grain boundary in the sample that used heat input of $18 \mathrm{~kJ} / \mathrm{cm}$. Figure $6 \mathrm{a}$ (Spectrum 1) revealed an increase of Carbone (C) of 7.6 \%, Mn (1.7\%) which result can be seen in Figure 6c. From the same Figure 6a, a second measurement was made (Spectrum 2) and the results showed an increase of C (13.3\%), $\mathrm{Cr}(1.2 \%)$, and Mn (1\%) (Figure 6e). The reason for the increase of the alloying element can be related to the formation of pro-eutectoid alloy-rich carbides in the microstructure caused by higher heat input and also the use of overmatched filler wire. Figure $6 \mathrm{~b}$ presents the EDS mapping points. Spectrum 1 and Spectrum 2 are the points that have been measured in the CGHAZ of the S960QC side. The results from Spectrum 1 revealed the increase of C (10.4\%), Cr (2.5\%), and Mn (1.6\%) (Figure 6d). Spectrum 2 presents the result of C (9.6\%), $\mathrm{Cr}(3.5 \%), \mathrm{Ni}(2.6 \%)$, and $\mathrm{Mn}(2.7 \%)$ on Figure 6f. In this last measurement, an increase of $\mathrm{Cr}, \mathrm{Mn}$, Ni weight \% compared to the base metal was noticed. The consequence of those increments can be the result of brittle formations in some areas of the HAZ mainly in martensitic microstructural constituents (tempered martensitic formations).

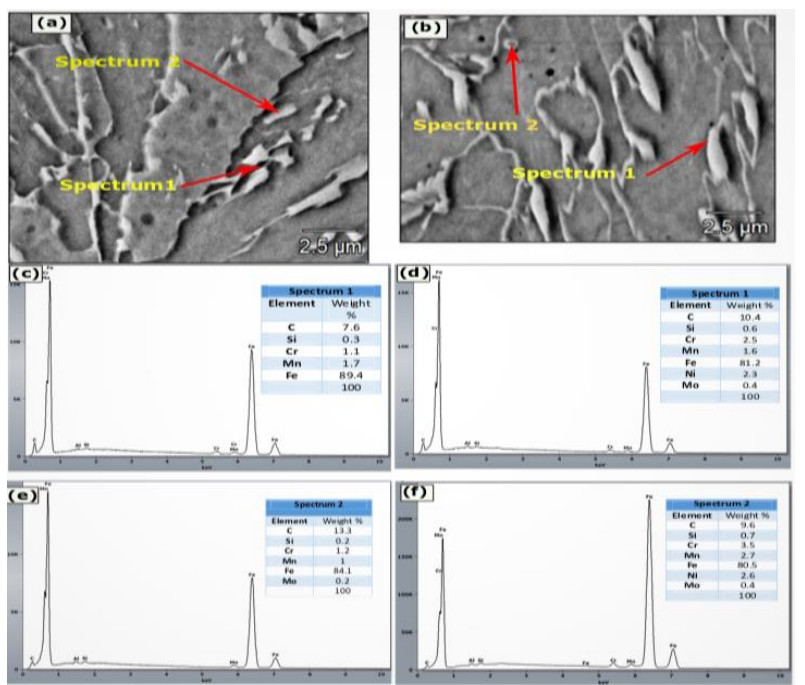

Fig. 6: Morphology and EDS Analysis of Carbides Formed at Prior Austenite Grain Boundaries in S700MC and S960QC at the Heat Input of 18 Kj/Cm (Austenitization Temperature of $960^{\circ} \mathrm{C}$ ).

\subsection{Tensile test results}

This picture shows the variation of ultimate tensile strength (UTS) function of the variation of elongation (A \%) before sample rupture. It is observed that the same behavior of UTS curves up to an elongation of about $3.4 \%$, which begin to disperse along horizontally. A maximum value elongation of $11.1 \%$ was observed at an average of UTS of $836.7 \mathrm{MPa}$, which value was applied with Q3. The average elongation and UTS values were determined for all samples, respectively; $\mathrm{A} 2=9.5 \%$, for UTS $=795 \mathrm{MPa}$ attributed to Q2, and A1 = 6.7\%, for UYS $=772.8 \mathrm{MPa}$ attributed to Q1. 


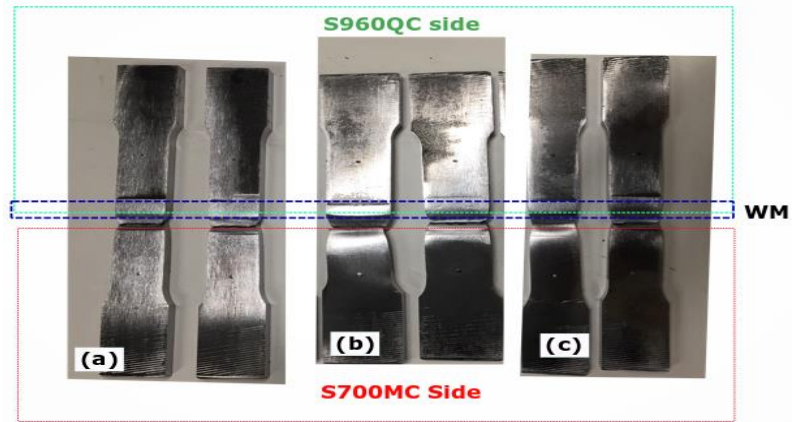

Fig. 7: Tensile Test Results Show the Fracture Location in the S700MC Side of the Welded Joints. A) Welded Sample of Heat Input with 8 Kj/Cm, B) Welded Sample with A Heat Input of $10 \mathrm{Kj} / \mathrm{Cm}$, and C) Welded Sample with A Heat Input of $18 \mathrm{Kj} / \mathrm{Cm}$.

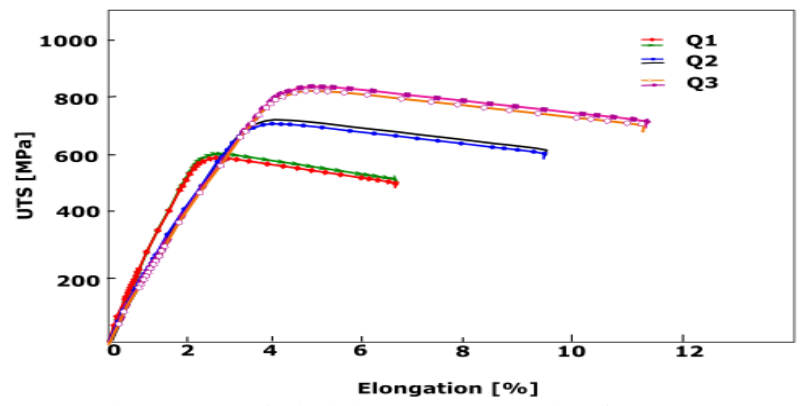

Fig. 8: Ultimate Tensile Strength of Dissimilar HSS Weld Joint of Three Heat Input Parameters.

The Tensile test results shown in Table 3, confirms a correlation between the heat input value of the welding process and microstructure behavior in the HAZ, and mechanical properties of the welded joints. In that Table 3, they were cooling time values, a yield strength (YS), an ultimate yield strength (UYS), elongation (A \%), and the ruptured place. The Tensile test confirms the softening observed in the FGHAZ of the S700MC, causing the break of the joint on its side during the test; this is seen in Figure 8. As shown in Figure 8 and Table 3 , the rupture was confirmed in the HAZ of S700MC.

Table 3: Average Tensile Values after the Cooling Process of Different Samples

\begin{tabular}{|c|c|c|c|c|c|c|}
\hline heat input [Q] & $\begin{array}{l}\text { Micro alloy elements composition in HAZ } \\
\text { S700MC }\end{array}$ & Cooling time [s] & $\mathrm{YS}$ [MPa] & UTS [MPa] & Elongation [\%] & Place of rupture \\
\hline $\mathrm{Q}_{1}(18 \mathrm{~kJ} / \mathrm{cm})$ & & 51 & $\begin{array}{l}702.0 \\
720.0 \\
711.0\end{array}$ & $\begin{array}{l}772.1 \\
773.5 \\
772.8\end{array}$ & $\begin{array}{l}6.5 \\
6.9 \\
6.7\end{array}$ & \\
\hline $\mathrm{Q}_{2}(10 \mathrm{~kJ} / \mathrm{cm})$ & $1.6 \mathrm{Mn}, 1.3 \mathrm{Ni}, 0.4 \mathrm{Mo}$ & 27.84 & $\begin{array}{l}749.0 \\
761.1 \\
755.0 \\
753.0\end{array}$ & $\begin{array}{l}794.6 \\
795.4 \\
795.0 \\
841.9\end{array}$ & $\begin{array}{l}9.3 \\
9.7 \\
9.5 \\
11.1\end{array}$ & HAZ S700MC \\
\hline $\mathrm{Q}_{3}(8 \mathrm{~kJ} / \mathrm{cm})$ & & 11.2 & $\begin{array}{l}795.0 \\
774.0 \\
\end{array}$ & $\begin{array}{l}831.5 \\
836.7 \\
\end{array}$ & $\begin{array}{l}11.1 \\
11.1 \\
\end{array}$ & \\
\hline
\end{tabular}

\section{Conclusion}

In this study, mechanical properties and microstructural constituents of dissimilar welded joints of S700MC/S960QC with overmatched filler wire were investigated. By applying different heat input values using the GMAW process, the samples were welded. Vickers Hardness and Tensile test were developed for mechanical parts. In the microstructural analysis, SEM and EDS spectroscopy was performed. The results obtained from such tests can be summarized as follows:

- They were a substantial hardness reduction in the fine grain HAZ of the S700MC side of welded joints when heat input of 18 $\mathrm{kJ} / \mathrm{cm}$ is applied. The decrease of hardness was also observed in the coarse grain HAZ of the S960QC side. The most softening zones were varied between 220-240 HV5 on the S700MC side, 250-260 HV5 on the S960QC side.

- The results of welding dissimilar S700MC/S960QC using overmatched filler wire with a heat input of $10 \mathrm{~kJ} / \mathrm{cm}$ stabilized hardness reduced softening areas in the HAZ.

- When SEM tests, microstructural constituents in the S700MC side were mainly the composition of Ferrite with carbide cluster. On the 960QC side, they were an increase of Tempered Martensite (TM) and the mixture of Bainite-Martensite. The microstructure of WM was essentially the formation of acicular ferrite (AF) and widmanstätten ferrite (WF).

- The result of EDS analysis revealed an increase in carbon (C), Chrome (Cr), Manganese (Mn), and Nickel (Ni) especially when heat input is increased up to $18 \mathrm{~kJ} / \mathrm{cm}$. The increase of carbide formation in the CGHAZ of both sides reduces the hardness and strength of the welded joints.

- The tensile test confirms the softening observed in the FGHAZ of the S700MC side, which caused the joint fracture on this side during the test. The maximum value of elongation $\%$ was observed at $11.1 \%$, which had an average UTS value of $836.7 \mathrm{MPa}$. 


\section{Acknowledgments}

The authors would like to thank the technical support from the Cameroon Welding Association (CWA).

\section{References}

[1] Arifin A, and Afriansyah, Dissimilar metal welding using shielded metal arc welding: A review, Technology Reports of Kansai University, Japon, 2020.

[2] Bayock N, Kah P, Mvola B, and Layus P, Experimental review of thermal analysis of dissimilar welds of high-strength steel, Review on Advanced Materials Science, vol. 58, 2019, 38-49. https://doi.org/10.1515/rams-2019-0004.

[3] Laitinen R, Improvement of weld HAZ toughness at low heat input by controlling the distribution of M_A constituents, OULU: ACTA UNIVERSITATIS OULUENSIS, 2006.

[4] Piotr S, and Maciej P, Study of microstructure, geometry, and properties of laser beam welded joints made of S960QL structural steel and S304 corrosion-resistant steel, Welding Technology Review, vol. 93, 2021, 1-22. https://doi.org/10.26628/wtr.v93i1.1127.

[5] Bayock N, Kah P, Salminen A, Belinga M, and Yang X, Feasibility study of welding dissimilar advanced and ultra-high-strength steels, Reviews on Advanced Materials Science, vol. 59, 2020, 57-66. https://doi.org/10.1515/rams-2020-0006.

[6] ISO, Specification and qualification of welding procedures for metallic materials - Welding procedure test — Part 1: Arc and gas welding of steels and arc welding of nickel and nickel alloys; ISO 15614-1: 2017, International Standard Organization, Geneva, Switzerland, 2017.

[7] Guo W, Crowther D, Francis J, Thompson A, Liu Z, and Li L, Microstructure and mechanical properties of laser-welded S960 high strength steel, Materials and Design, vol. 85, 2015, 534-548. https://doi.org/10.1016/j.matdes.2015.07.037.

[8] Mikko H, Atef H, Markku K, Matias J, Jani K, and Antti J, Microstructural evolution and tensile strength of laser-welded butt joints of ultra-highstrength steels: low and high alloy steels, Key Engineering Materials, vol. 883, 2021, 250-257. https://doi.org/10.4028/www.scientific.net/KEM.883.250

[9] Robertson S M, Frostevarg J, Ramasamy A, Kalfsbeek B, and Kaplan H, Microstructures of high-strength steel welding consumables from directed thermal cycles by shaped laser pulses, The International Journal of Advanced Manufacturing Technology, vol. 109, 2020, $2653-2662$. https://doi.org/10.1007/s00170-020-05749-1.

[10] Yamamoto H, and Ito K, Effect of microstructural modification using friction stir processing on fatigue strength of butt-joints for high strength steels, Materials Sciences and Applications, vol. 9, 2018, 625-636. https://doi.org/10.4236/msa.2018.97045.

[11] Siltanen J and Tihinen S, Position welding of $960 \mathrm{MPa}$ ultra high strength steel, Journal of Laser Application, 2012. https://doi.org/10.2351/1.5062489.

[12] Zajac S, Schwinn V, and Tacke H, Characterization and quantification of complex bainitic Microstructures in high and ultra-high-strength line pipe steels, Materials Science Forum, 2005, 387-394. https://doi.org/10.4028/0-87849-981-4.387.

[13] Majlinger K, Kalacska E, and Spena P R, Gas metal arc welding of dissimilar AHSS sheets, Materials and Design, vol. 109, 2016, 615-621. https://doi.org/10.1016/j.matdes.2016.07.084

[14] Bayock N, Kah P, Layus P, and Karkhin V, Numerical and experimental investigation of heat input effect on the mechanical properties and microstructure of dissimilar weld joints of 690-MPa QT and TMCP steel, metals, vol. 9, 2019, 1-19. https://doi.org/10.3390/met9030355.

[15] Bhanu V, Fydrych D, and Pandey A, Study on microstructure and mechanical properties of a laser-welded dissimilar joint of P91 Steel and Incoloy 800HT Nickel alloy, materials, vol. 14, 2021, 1-12. https://doi.org/10.3390/ma14195876.

[16] Derakhshan D, Yazdian N, Craft B, Smith S, and Kovacevic R, Numerical simulation and experimental validation of residual stress and welding distortion induced by laser-based welding processes of thin structural steel plates in butt joint configuration, Optics and Laser Technology, vol. 104 2018 170-182. https://doi.org/10.1016/j.optlastec.2018.02.026.

[17] Gorka J, Microstructure and properties of high-temperature (HAZ) of thermo-mechanically treated S700MC high yield strength steel, Materials and Technology, vol. 50, 2016, 617-621. https://doi.org/10.17222/mit.2015.123.

[18] Gorka J and Stano S, Microstructure and properties of hybrid laser arc welded joints (Laser beam-MAG) in thermo-mechanical control processed S700MC steel, metals, 2018, 1-15. https://doi.org/10.3390/met8020132.

[19] Bayock N, Kah P, Mvola B, and Layus P, Effect of heat input and undermatched filler wire on the microstructure and mechanical properties of dissimilar S700MC/S960QC high-strength steels, metals, vol. 9, 2019, 1-20. https://doi.org/10.3390/met9080883.

[20] Chen Y, Yang C, Chen H, Zhang H, and Chen S, Microstructure and mechanical properties of HSLA thick plates welded by novel double-sided gas metal arc welding, International Journal of Advanced Manufacturing Technology, vol. 78, no. 457, 2015, 1-13. https://doi.org/10.1007/s00170014-6477-0.

[21] Zhu Y, Liu L, Gou Q, Gao W, Effect of heat input on the interfacial characterization of the butter joint of hot-rolling CP-Ti/Q235 bimetallic sheets by laser+CMT, Scientific reports, vol. 11, 2021, no. 10020. https://doi.org/10.1038/s41598-021-89343-9.

[22] Ali M, Porter D, Kömi J, and Eissa M, Effect of cooling rate and composition on microstructure and mechanical properties of ultra-high-strength steels, Journal of Iron and Steel Research International, 2019. https://doi.org/10.1007/s42243-019-00276-0.

[23] Guo W, Li L, Dong S, Crowther D, and Thompson A, Comparison of microstructure and mechanical properties of ultra-narrow gap laser and gasmetal-arc welded 960 high strength steel, Optics and Lasers in Engineering, vol. 91, 2017, 1-15. https://doi.org/10.1016/j.optlaseng.2016.11.011.

[24] Haslberger P, Holly S, Ernst W, and Schnitzer R, Microstructure and mechanical properties of high-strength steel welding consumables with a minimum yield strength of 1100 MPa, Journal of Materials Science, vol. 53, 2018, 6968-6979. https://doi.org/10.1007/s10853-018-2042-9.

[25] Keehan E, Zachrisson J, and Karlsson J, Influence of cooling rate on microstructure and properties of high strength steel weld metal, Science Technology Welded Joints, vol. 15, 2010, 3. https://doi.org/10.1179/136217110X12665048207692.

[26] Wen C, Wang Z, Deng X, Wang G, and Misra D, Effect of heat input on the microstructure and mechanical properties of low alloy ultra-highstrength structural steel welded joint, Steel Research International, vol. 89, 2018, 1700500. https://doi.org/10.1002/srin.201700500.

[27] Miletic I, Ilic A., Nikolic R, Ulewicz R, Lozica S, and Norbert I, Analysis of Selected properties of welded joints of the HSLA steels, materials, vol 13, 2020, 1301, 1-12. https://doi.org/10.3390/ma13061301.

[28] Scutelnicu E, Iordachescu M, Catalina R C, Mihailescu D, and Ocana J L, Metallurgical and mechanical characterization of low carbon steelstainless steel dissimilar joints made by laser autogenous welding, metals, vol. 11, 2021, 1-11. https://doi.org/10.3390/met11050810.

[29] Tadashi F, Shin-ya A, and Goro M, Anisotropic Ferrite growth and substructure formation of Bainite transformation in Fe-9Ni-C alloys: In-Situ Measurement, Materials Transaction, vol. 59, 2018, 214-223. https://doi.org/10.2320/matertrans.MC201714.

[30] Gould J, Khurana S, and Li T, A combination of thermal and microstructural modeling can be used to estimate the performance of welds in advanced high-strength steels, Welding Research, , 2006, 116-s.

[31] Villalobos J, Del-Pozo A, Campillo B, Mayen J, and Serna S, Micro-alloyed steels through history until 2018: Review of chemical composition, processing and hydrogen service, metals, vol. 8, 2018, 41-49. https://doi.org/10.3390/met8050351.

[32] H. He, F. Forouzan, S. M. Robertson and E. Vuorinen, Microstructure and mechanical properties of laser-welded DP steels used in the automotive industry, materials, vol. 14, no. 456, 2021, 1-14. https://doi.org/10.3390/ma14020456.

[33] J. Xue, W. G. Peng Peng, M. Xia, Z. W. Caiwang Tan, and H. Z. a. Y. Li, HAZ characterization and mechanical properties of QP980-DP980 laser welded joints, Chinese Journal of Mechanical Engineering, vol. 34, no. 80, 2021 1-14. https://doi.org/10.1186/s10033-021-00596-x.

[34] P. Suikkanen, Development, and processing of low carbon bainitic steels, Oulu: University of Oulu, 2009. 
[35] A. Navarro-Lopez, J. Hidalgo, J. Sietsma, and M. Santofimia, Characterization of bainitic/martensitic structures formed in isothermal treatments below the Ms Temperature, Materials Characterization, 2017, 248-256. https://doi.org/10.1016/j.matchar.2017.04.007.

[36] ISO, International standard test methods for tensile testing of metallic materials; ISO 6892-1, International Standard Organization, Geneva, Switzerland, 2016.

[37] ISO, International standard test methods for micro indentation Hardness of materials; ISO 6507-1:2018, International Standard organization, Geneva, Switzerland, 2018. 